\title{
Synthesis of Novel Pinocembrin Amino Acid Derivatives and Their Antiaging Effect on Caenorhabditis elegans via the Modulating DAF-16/ FOXO [Corrigendum]
}

\author{
Wang W, Feng X, Du Y, et al. Drug Des Devel Ther. \\ 2021;15:4177-4193. \\ Page 4191, Acknowledgments, line 2, the text \\ “2020071620211” should read "2018YFC1706505".
}

\section{Publish your work in this journal}

Drug Design, Development and Therapy is an international, peerreviewed open-access journal that spans the spectrum of drug design and development through to clinical applications. Clinical outcomes, patient safety, and programs for the development and effective, safe, and sustained use of medicines are a feature of the journal, which has also
The authors apologize for this error. 